\title{
Cullin-4 regulates Wingless and JNK signaling-mediated cell death in the Drosophila eye
}

\author{
Meghana Tare ${ }^{1,5}$, Ankita Sarkar ${ }^{1}$, Shimpi Bedi ${ }^{1}$, Madhuri Kango-Singh ${ }^{1,2,3}$ and Amit Singh ${ }^{\star, 1,2,3,4}$
}

In all multicellular organisms, the fundamental processes of cell proliferation and cell death are crucial for growth regulation during organogenesis. Strict regulation of cell death is important to maintain tissue homeostasis by affecting processes like regulation of cell number, and elimination of unwanted/unfit cells. The developing Drosophila eye is a versatile model to study patterning and growth, where complex signaling pathways regulate growth and cell survival. However, the molecular mechanisms underlying regulation of these processes is not fully understood. In a gain-of-function screen, we found that misexpression of cullin-4 (cul-4), an ubiquitin ligase, can rescue reduced eye mutant phenotypes. Previously, cul-4 has been shown to regulate chromatin remodeling, cell cycle and cell division. Genetic characterization of cul-4 in the developing eye revealed that loss-of-function of cul4 exhibits a reduced eye phenotype. Analysis of twin-spots showed that in comparison with their wild-type counterparts, the cul-4 loss-of-function clones fail to survive. Here we show that cul-4 clones are eliminated by induction of cell death due to activation of caspases. Aberrant activation of signaling pathways is known to trigger cell death in the developing eye. We found that Wingless $(\mathrm{Wg})$ and c-Jun-amino-terminal-( $\mathrm{NH}_{2}$ )-Kinase (JNK) signaling are ectopically induced in cul-4 mutant clones, and these signals colocalize with the dying cells. Modulating levels of $\mathrm{Wg}$ and JNK signaling by using agonists and antagonists of these pathways demonstrated that activation of Wg and JNK signaling enhances cul-4 mutant phenotype, whereas downregulation of Wg and JNK signaling rescues the cul-4 mutant phenotypes of reduced eye. Here we present evidences to demonstrate that cul- 4 is involved in restricting $\mathrm{Wg}$ signaling and downregulation of JNK signaling-mediated cell death during early eye development. Overall, our studies provide insights into a novel role of cul-4 in promoting cell survival in the developing Drosophila eye.

Cell Death and Disease (2016) 7, e2566; doi:10.1038/cddis.2016.338; published online 29 December 2016

During organogenesis, regulation of conserved processes like cell proliferation, cell survival and cell death is crucial for organ growth and differentiation. A fine balance between control of cell death and cell survival is responsible for final organ shape and size during development. We used Drosophila eye model to identify genes involved in promoting growth and cell survival. The Drosophila adult eye contains 750-800 differentiated ommatidia, and develops from a sac-like epithelial structure called the imaginal disc housed in the larva. The ommatidia differentiate in the wake of a synchronous wave of retinal differentiation called the Morphogenetic Furrow (MF). ${ }^{1}$ The MF originates at the posterior eye margin, and the Wingless $(\mathrm{Wg})$ signaling pathway negatively regulates the anterior movement of the MF. ${ }^{2-4} \mathrm{Wg}$, a secreted morphogen, initiates an intracellular signaling cascade by binding to its receptors Arrow (Arr) and Frizzled (Fz), which triggers downstream events to control the nuclear localization of the
Drosophila beta-catenin Arm, and the spatial expression of Wg target genes. ${ }^{5-7}$ In Drosophila eye, $\mathrm{Wg}$ is also known to induce the proapoptotic genes, head involution defective (hid), reaper (rpr) and grim (together referred as $\mathrm{HRG}$ ), to trigger programmed cell death to remove extra cells from the periphery of the pupal retina. ${ }^{8-13}$ Further, aberrant signaling during development, e.g., abnormal Wg signaling, also causes stress-induced apoptosis. ${ }^{14}$

The intrinsic caspase-dependent cell death involves activation of $\mathrm{HRG},{ }^{15-17}$ which are negatively regulated by Drosophila inhibitor of apoptosis (DIAPs). ${ }^{18,19}$ Inactivation of DIAP-1 can trigger cell death by the activation of cysteine proteases Dronc and Drice, the Drosophila homolog of Caspase- 9 and Caspase-3, respectively. ${ }^{20,21-23}$ In Drosophila expression of baculo-virus protein, P35 can block caspasedependent cell death. ${ }^{24}$ Besides $\mathrm{Wg}$, activation of $\mathrm{c}$-Jun amino-terminal $\left(\mathrm{NH}_{2}\right)$ Kinase $(\mathrm{JNK})$ signaling triggers cell

\footnotetext{
${ }^{1}$ Department of Biology, University of Dayton, Dayton, OH, USA; ${ }^{2}$ Premedical Program, University of Dayton, Dayton, OH, USA; ${ }^{3} \mathrm{Center}$ for Tissue Regeneration and Engineering at Dayton (TREND), University of Dayton, Dayton, OH, USA and ${ }^{4}$ Center for Genomic Advocacy (TCGA), Indiana State University, Terre Haute, IN, USA

*Corresponding author: A Singh, Department of Biology, Center for Tissue Regeneration and Engineering at Dayton (TREND), University of Dayton, 300 College Park, Dayton, Ohio 45469-2320, USA. Tel: 937-229-2894; Fax: 937-229-2021; E-mail: asingh1 @udayton.edu

${ }^{5}$ Current address: Molecular, Cell and Cancer Biology, University of Massachusetts Medical School, Worcester, MA 01605, USA

Abbreviations: Cul-4, Cullin-4; Wg, Wingless; JNK, c-Jun amino-terminal $\left(\mathrm{NH}_{2}\right)$ Kinase; MF, Morphogenetic Furrow; Arm, Armadillo; dTCF, Drosophila T cell factor; Arr, Arrow; Fz, Frizzled; Sgg, Shaggy; Hid, head involution defective; Rpr, reaper; HRG, hid, reaper, and grim; DIAP1, Drosophila inhibitor of Apoptosis; PCD, programmed cell death; Cas-9, caspase-9; Cas-3, Caspase-3; TNF, Tumor necrosis factor; Egr, Eiger; Wgn, Wengen; Tak1, TGF $\beta$ activating kinase 1; Hep, hemipterous; Bsk, basket; $\mathrm{Bsk}^{\mathrm{DN}}$, basket dominant negative; Puc, puckered; L, Lobe; Ey, eyeless; UAS, Upstream Activator Sequence; Cl, cell lethal; Bi, bifid; DV, Dorso-ventral; GFP, Green Fluorescent Protein; FLP, Flippase; ACF, after clone formation; RNAi, RNA interference; N, Notch; Hh, Hedgehog; Neu, Neuralized; Mib, Mind Bomb; Yki, yorkie; Cul-3, Cullin-3; RNF, Ring finger proteins; NIG, National Institute of Genetics; Twi, twist; FRT, Flippase recombination targets; AEL, after egg laying; Dlg, disc large; $\beta$, beta; Elav, embryonic lethal, abnormal vision; IgG, Immunoglobulin G; FITC, Fluorescein isothiocyanate; Cy3, Cyanines 3 dye; Cy5, Cyanines 5 dye

Received 27.7.16; revised 08.9.16; accepted 09.9.16; Edited by E Baehrecke
} 

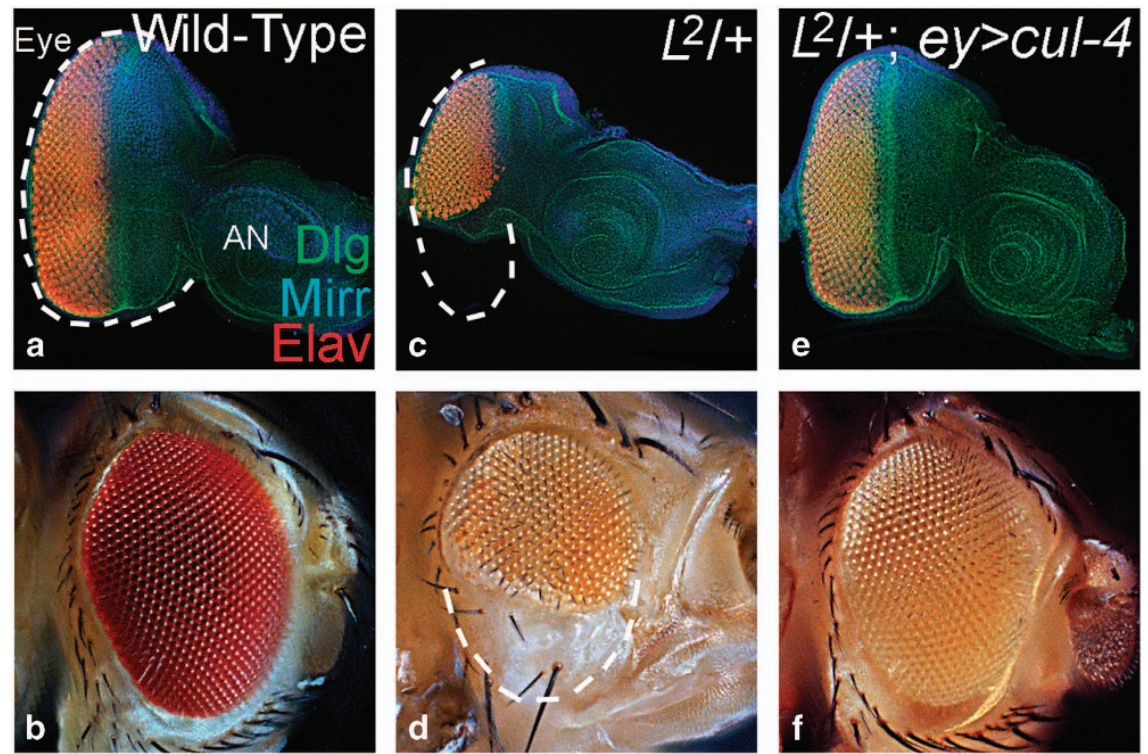

Figure 1 Gain-of-function of cul-4 can rescue reduced eye mutant phenotype. (a and $\mathbf{b}$ ) Wild-type (a) eye-antennal imaginal disc and (b) adult eye. The eye disc is stained for a membrane specific marker, Dlg (green); dorsal eye fate marker, Mirr (blue); and pan-neural marker, Elav (red). The white dotted line marks the boundary of eye field. (c and d) $L^{2}$ mutant exhibits reduced eye phenotype in (c) eye imaginal disc and (d) adult eye. (e and f) Misexpression of cul-4 in the $L^{2}$ mutant eye background ( $L^{2}$; ey $>$ cul-4) results in a significant rescue to a near wild-type eye as seen in (e) the eye disc and (f) the adult eye

death through the activation of caspases. ${ }^{11,14,25-27}$ JNK belongs to a conserved MAP kinase super-family, which is involved in cell proliferation and cell survival, and is activated through a cascade of phosphorylation by MAP kinases. ${ }^{26,28-30}$ In Drosophila, JNK signaling is activated by binding of the tumor necrosis factor (TNF) Eiger (Egr) to its receptor Wengen (Wgn), and a conserved signaling cascade of Tak 1 (TGF $\beta$ activating kinase 1 , a Jun kinase kinase kinase (JNKKK), hemipterous (hep) (Jun kinase kinase), basket (bsk) (Jun kinase) and jun. Activation of the pathway leads to expression of the downstream target puckered (puc), a dual phosphatase, which participates in a negative feedback loop by downregulating JNK activity. ${ }^{29,30}$

We argued that during early eye development, $\mathrm{Wg}$ or JNK levels must be tightly regulated to allow differentiation to proceed, and to prevent premature cell death that results in small or reduced eye phenotype. In a genetic screen, we identified cullin4 (cul-4) as a modifier that rescues the reduced eye phenotype. ${ }^{31}$ During development cul-4 is globally required. Analysis of cul-4 function revealed its new role in promoting cell survival during early eye development. The cul-4 gene belongs to an evolutionary conserved class of Cullin-family E3 ubiquitin ligases. ${ }^{32}$ Earlier studies showed that cul-4 is involved in maintenance of genomic integrity by promoting the ubiquitylation and subsequent degradation of key regulators of cell cycle progression. ${ }^{33-36}$ Here, we report that cul-4 promotes cell survival by preventing $\mathrm{Wg}$ and JNK signaling-mediated cell death in the developing eye.

\section{Results}

Gain-of-function of cul-4 rescues reduced eye mutant phenotype. In comparison with the wild-type larval eye disc and the adult eye (Figures $1 \mathrm{a}$ and $\mathrm{b}$ ), $L$ mutant exhibits reduced eye phenotype in larval eye disc (Figure 1c) and adults (Figure 1d) ${ }^{11,37}$ Misexpression of cul-4 using Gal4/UAS approach ${ }^{38}\left(L^{2} ;\right.$ ey $>$ cul-4) resulted in the rescue of $L^{2}$-reduced eye phenotype (Figures $1 \mathrm{e}$ and f). Misexpression of cul-4 (ey>cul-4) does not affect the eye size (not shown) suggesting that cul-4 may not promote cell proliferation. We analyzed loss-of-function phenotype of cul-4 to understand its role during eye development.

Loss-of-function of cul-4 fail to survive and exhibit reduced eye phenotype. We generated cul-4 loss-offunction clones by cell lethal (cl) approach, which results in an eye disc comprising of nearly $80 \%$ mutant cells due to elimination of the wild-type twin spot by a $\mathrm{Cl}$ mutation. ${ }^{39}$ Loss-of-function clones of cul-4 alleles (Figure 2a) ${ }^{40}$ like cul-4 ${ }^{E \times G 1-3}$ (Figure 2c) or cul-4 ${ }^{J J 11}$ (Figures 2d and e) resulted in a small eye phenotype as compared with the wildtype eye (Figure 2b). It is to be noted that both $\mathrm{cul}^{\mathrm{JJ11}}$ and cul-4 $4^{E X G 1-3}$ loss-of-function phenotypes were similar in the eye. Downregulation of cul-4 expression in the dorso-ventral (DV) margins of developing eye disc by using bi-Gal4 driver (Figure 2f; bi> GFP) resulted in reduction of eye field on DV margins (Figures $2 \mathrm{~g}$ and $\mathrm{h}$, arrows). ${ }^{41,42}$ It suggests that there is no domain constraint in cul-4 function in the eye. It is possible that reduced eye phenotype may be due to induction of cell death. To test this, we used ey-Flippase (ey-Flp) to induce somatic 'twin clones' using Ubi-GFP (1XGFP), where cul- $4^{-/-}$mutant cells (GFP-negative) were adjacent to their wild-type twin spot (2XGFP). However, we found that only the wild-type twin clone (2XGFP) and the heterozygous cells (express 1XGFP) could be identified. However, we found wild-type twin clones (2XGFP) but no cul-4 mutant clones (GFP-negative) in the third-instar eye disc (not shown), suggesting that the cul-4 mutant cells failed to survive. We 

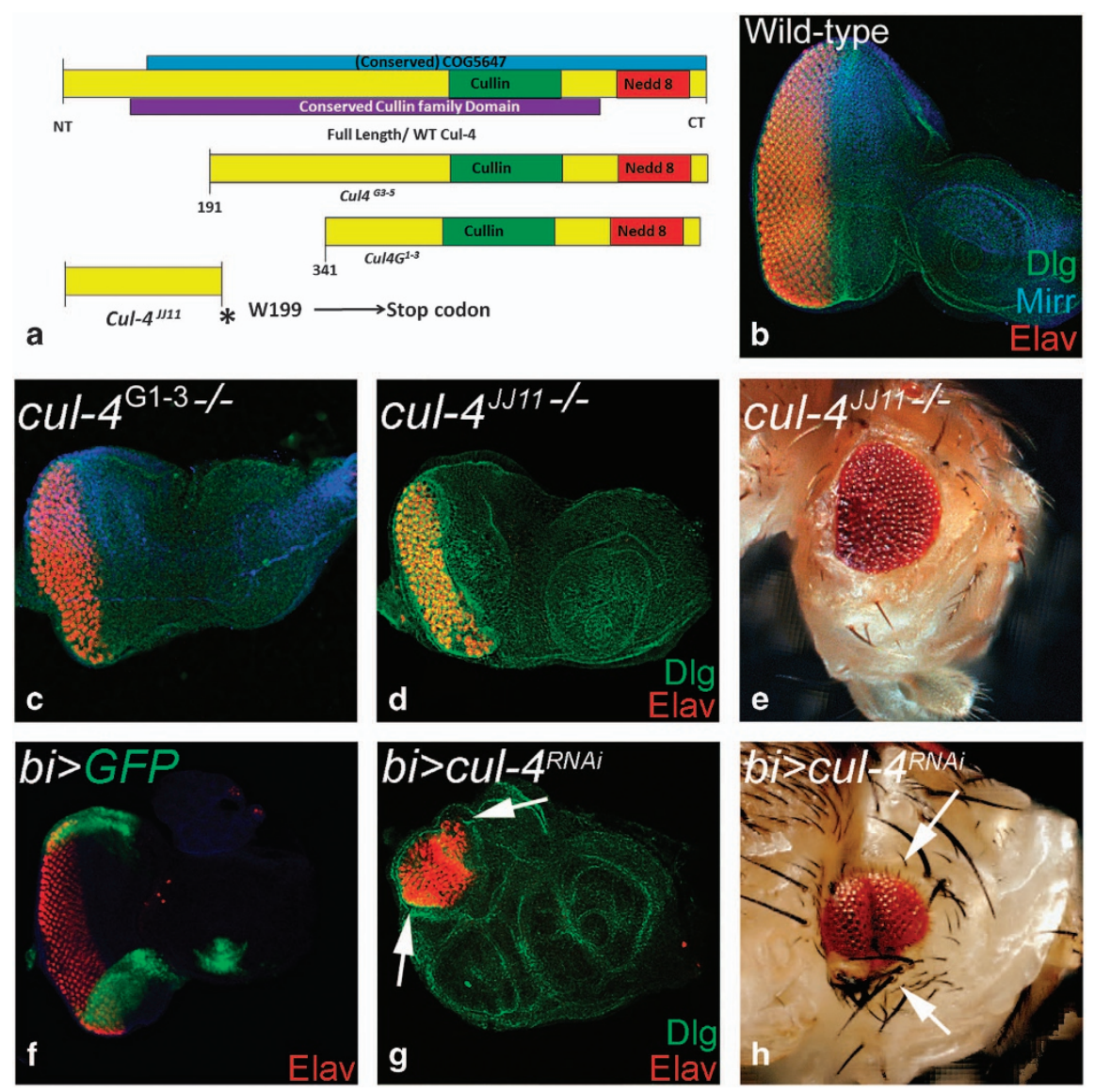

Figure 2 Loss-of-function of cul-4 results in reduced eye phenotype. (a) Schematic representation of wild-type and truncated Cul-4 protein encoded by different mutant alleles of cul-4 used in the loss-of-function studies. ${ }^{40}$ (b) Wild-type eye disc stained for dorsal fate marker Mirr (blue), Dlg (green) and Elav (red). (c-e) Loss-of-function clones of cul-4 (e) cul-4 ${ }^{G 1-3}(\mathbf{d}$ and $\mathbf{e})$ cul-4 ${ }^{J 11}$ generated by using 'cell-lethal' approach ${ }^{39}$ results in reduced eye phenotype as seen in (c and d) eye imaginal disc and (e) adult eye. (f) bi-Gal4 drives expression of GFP reporter on DV of the eye imaginal disc. ( $g$ and $\mathbf{h}$ ) Misexpression of cul-4 ${ }^{\mathrm{RNAi}}$ on DV margins of the eye using bi-Gal4 driver (bi $\left.>c u l 4^{\mathrm{RNA}}\right)$ exhibits eye fate suppression on both DV margins as seen in (h) eye disc and the (i) adult eye

performed a 'twin spot' analyses in the heat-shock-Flippase (hs-FLP) -induced clones, to test survival profiles of cul-4 mutant cells. The heat shock was administered in the first instar larva and the resultant clones were examined in the second(24 h after clone formation (ACF)) and third-instar (48-72 h after clone formation) disc to determine whether or not these clones could survive. Very small clones were detected at second instar stage (within $24 \mathrm{~h}$ after clone formation). However, within $48 \mathrm{~h}$ after clone formation, the mutant clones were lost. In comparison with the wild-type clones (Figure 3a), the mutant clones generated at later time points (second instar (48 h) or early third instar $(60 \mathrm{~h})$ ) and examined at late thirdinstar stage (within $24 \mathrm{~h}$ after clone formation), showed smaller cul $-4^{-/}$clones (Figures $3 \mathrm{~b}$ and c; clone boundary marked by red dotted lines). These $\mathrm{cul}-4^{-/}$clones failed to survive until $120 \mathrm{~h}$ of development. Quantification of clone size showed that cul-4 mutant clones are significantly smaller than their wild-type twin clones (Figure 3c), suggesting that cul-4 mutant clones either fail to survive or are slow growing compared with wildtype cells. We tested if cul-4 mutant cells are eliminated by cell death using TUNEL labeling. ${ }^{11,17}$ Wild-type eye disc showed few TUNEL-positive dying cells (Figures 3d and d'), whereas eye disc lacking cul-4 function in the entire eye disc (cul-4ij11 $/-$,
Figures $3 e$ and $e^{\prime}$ ) or on DV margins ( $b i>c u l 4^{\text {RNAi }}$, Figures $3 f$ and f') showed a threefold increase in TUNEL-positive cells suggesting that $c u l-4$ mutant cells are eliminated by cell death.

cul-4 prevents cell death in the developing eye. We, therefore, tested if Drosophila Caspases- Dronc and Drice activation is part of the mechanism. In the eye disc, cul- $4^{J J 11}$ loss-of-function clones generated by 'cell-lethal' clonal approach, ${ }^{39}$ exhibited robust induction of activated Caspase- $3^{*}\left(\right.$ Cas $\left.-3^{\star}\right)$ and a signaling molecule Wg (Figures $4 \mathrm{a}$ and a"). Similarly, in semi-quantitative western blots, Dronc levels were nearly two fold higher in cul-4 mutant as compared with the wild-type eye disc (Figure 4b). Thus, both Dronc and Drice are induced in cul-4 mutant cells. Misexpression of baculo-virus P35 in the cul-4 loss-of-function clones (cul-4 $4^{J J 11-/-}$, ey>P35) resulted in a significant rescue of the reduced eye phenotype (Figures $4 c$ and c"). In cul-4 loss-offunction background reducing level of proapoptotic genes using H99 deficiency ${ }^{43}$ (cul-4 ${ }^{J 11-/-}, H_{99} /+$ ) resulted in significant rescue of the cul-4 mutant phenotype (Figures $4 \mathrm{e}$ and e"). It suggests that activation of caspases triggers apoptosis in cul-4 mutant cells. Aberrant signaling from key developmental and 

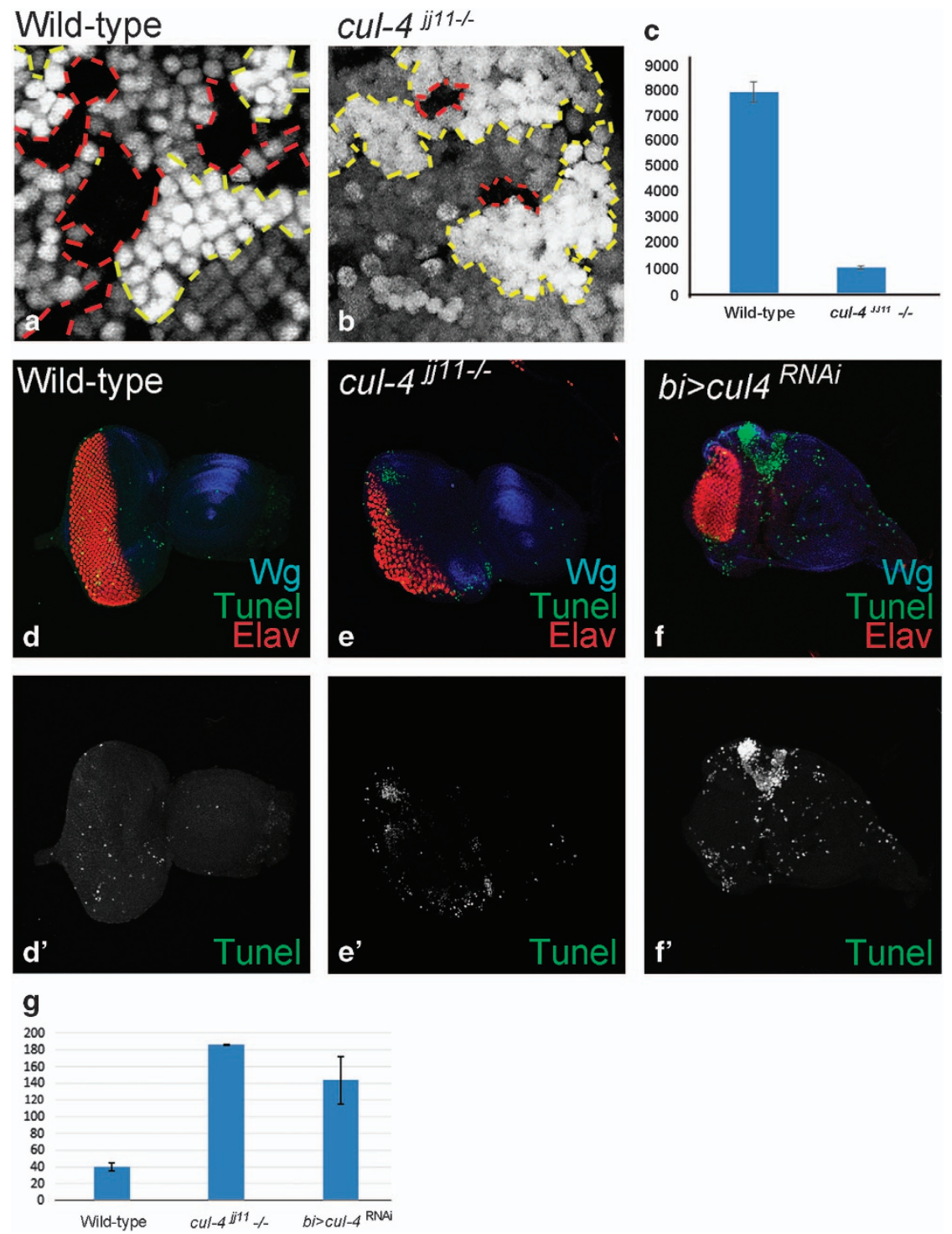

Figure 3 Loss-of-function clones of cul-4 fail to survive. (a and $\mathbf{b}$ ) Genetic mosaics generated by using a Flp-FRT system in the eye results in GFP-positive and GFP-negative patches of cells. (a) Note that in wild-type controls, clonal areas marked by the absence of GFP (red dotted lines) are comparable in terms of size to the wild-type clones (with strong (2X) GFP-positive areas, marked by red dotted lines). (b) Loss-of-function clones of cul-4J11 mutant in the eye imaginal disc (no GFP, marked by red dotted line) are smaller compared with the wild-type twin spot (2XGFP, marked by yellow dotted line). Note that these cul-4 $4^{J 11}$ mutant clones fail to survive 24 h after they are formed. Only GFP-positive (wild-type) cells were seen. (c)The cell number of cul-4 clones was less than eightfold as compared with the wild-type clones based on counting five eye discs for each. (d-f') TUNEL staining was used to mark the dying cells nuclei in ( $\mathbf{d}$ and $\mathbf{d}^{\prime}$ ) wild-type, (e and $\left.\mathbf{e}^{\prime}\right)$ cul-4ij11 $-/$ - clones and ( $\mathbf{f}$ and $\left.\mathbf{f}^{\prime}\right)$ bi $>$ cull ${ }^{\text {RNAi }}$ eye imaginal disc. (g) The dying nuclei were counted from five imaginal discs from each of these category. There is more than fourfold increase in dying cell population in cul-4 mutant eye disc as compared with wild-type

signaling pathways, like $\mathrm{Wg} / \mathrm{Wnt}$, can induce apoptosis to prevent defective development. ${ }^{10,14}$

cul-4 represses $\mathbf{W g}$ levels in the developing eye. In the third-instar stage, $\mathrm{Wg}$ is expressed along the antero-lateral margins of the wild-type eye disc (Figures 5a and $a^{\prime}$ ). Reducing cul-4 function on DV margin of eye disc using bi-Gal4 driver (bi>cul-4 ${ }^{\mathrm{RNAi}}$ ) resulted in strong ectopic induction of $\mathrm{Wg}$ in DV domain of the eye (Figures $5 \mathrm{~b}$ and b"; white arrows). Loss-of-function clones of cul-4 using

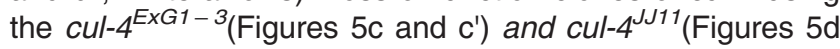
and $\mathrm{d}^{\prime}$ ) alleles showed a robust ectopic induction of $\mathrm{Wg}$ in the eye disc (Figures 5c', white arrows). Wg levels were significantly upregulated in semi-quantitative western blots on total protein isolated from eye imaginal discs from wild-type, and $\mathrm{cul}-4^{\mathrm{EXG1}-3}$ and $\mathrm{Cul}^{-4^{J J 11}}$ (Figure $5 \mathrm{e}$ ). These data suggest that cul-4 may downregulate $\mathrm{Wg}$ in the eye imaginal disc. Misexpression of $w g$ on DV margins of eye disc $b i>w g$ results in ectopic $w g$ transcription suggesting that $w g$ is a target of Wg pathway in developing eye (Supplementary Fig. S1). We then tested if aberrant $\mathrm{Wg}$ signaling is responsible for cul-4 mutant phenotypes.

Wg signaling pathway alters the cul-4 mutant phenotype. Arm translocates to the nucleus in response to $\mathrm{Wg}$ signaling and binds with the transcription factor dTCF (LET/TCF family 

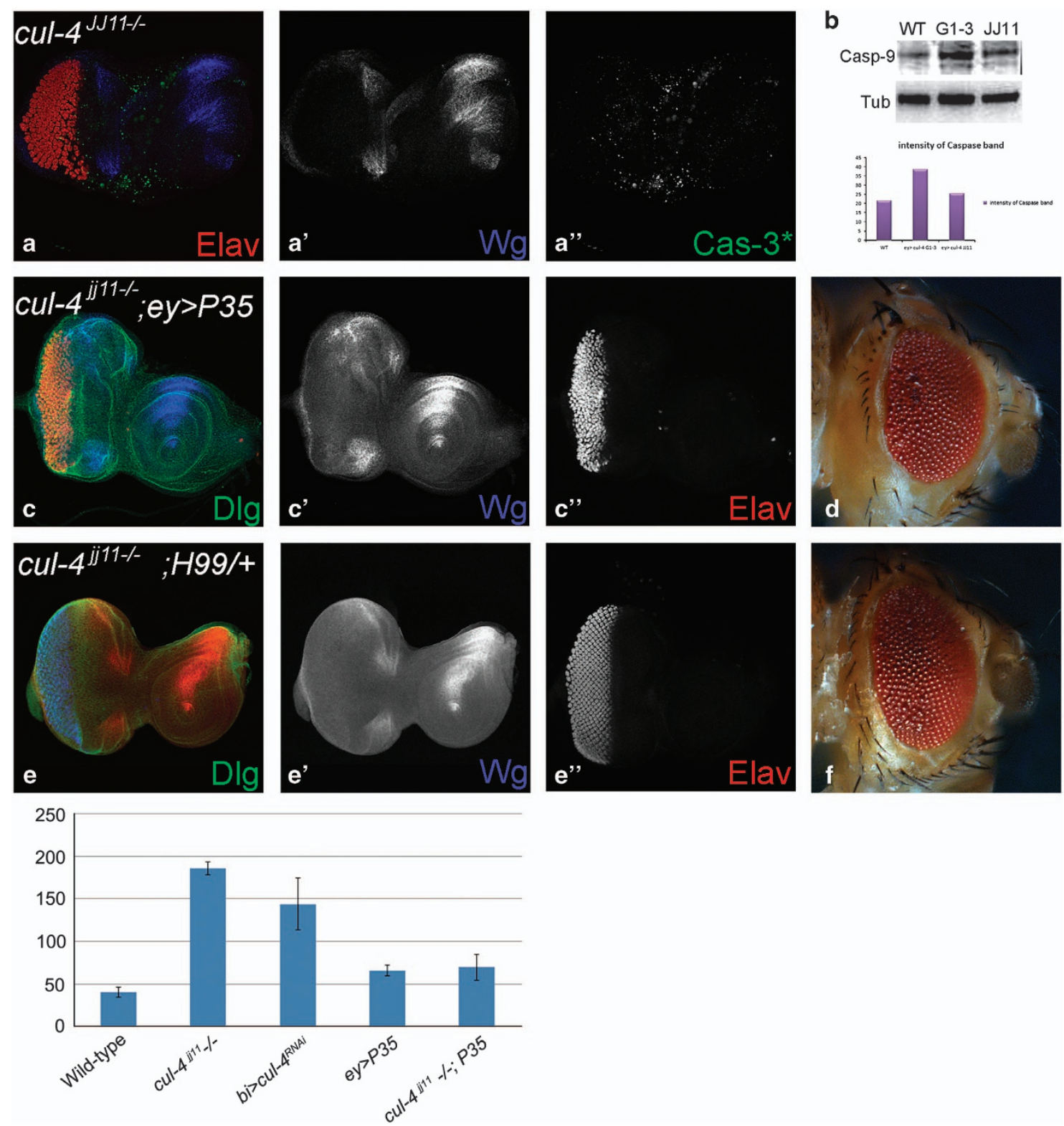

Figure 4 cul-4 mutant cells are eliminated by activation of caspases. (a, a' and a") Loss-of-function of cul-4 in eye results in enhanced caspase- $3^{\star}$ (cas- $3^{\star}$, green) levels along with Wg (blue) upregulation and suppression of eye fate based on Elav (red) expression. (b) In comparison with the wild-type controls, nearly twofold increase in activator caspase-9 protein are seen in total protein extracted from eye imaginal discs of cul-4 loss-of-function background. Caspase band staining intensity calculated by Image -J. (c and d) Loss-of-function phenotype of cul-4 can be rescued by misexpression of baculo-virus protein, P35 (cul- ${ }^{-/}$; ey $>$P35) as seen in (c, c' and c") eye imaginal disc and (d) adult eye. (e and f) Reduction in the levels of Hid-Reaper-Grim (HRG) complex by using deficiency of H99 can rescue the loss-of-function phenotype of cul-4, as seen in (e, e' and e") eye imaginal discs and (f) adult eye. (g) The dying nuclei were counted from five imaginal discs from each of these category. Misexpression of P35 can significantly reduce the number of dying cell nuclei in cul-4 loss-of-function eye disc as compared with wild-type

protein) to turn on the transcription of $\mathrm{Wg}$ target genes (Figure 6a). ${ }^{44}$ In western blots a two fold increase in Arm protein levels was observed in cul-4 mutant eye discs as compared with wild-type (Figure 6b). We tested if modulating Wg signaling levels can affect the cul-4 mutant phenotype. In the eye imaginal discs, activation of $\mathrm{Wg}$ signaling by misexpression of $w g(e y>w g)$ (Figure 6c) or arm (ey>arm) (Figure 6f) resulted in reduced eye phenotypes. ${ }^{11}$ Misexpression of $w g$ (cul-4 $\left.{ }^{J J 11-/-}, e y>w g\right)$ (Figures $6 \mathrm{~d}$ and e) or arm (cul-4 $4^{J J 11}$, ey $>$ arm) (Figures $6 \mathrm{~g}$ and $\mathrm{h}$ ) in cul-4 loss-of-function background, resulted in near complete loss of eye. Blocking
Wg signaling by misexpression of a constitutive active form of Shaggy/Zeste-White-3/GSK-3 (Sgg), a negative regulator of the $\mathrm{Wg}$ signaling pathway ${ }^{4,45}\left(e y>s g g^{S 9 A}\right)$ (Figure 6i) ${ }^{11}$ or dominant negative form of TCF $\left(d T C F^{D N}\right)^{44}\left(e y>d T C F^{D N}\right)$ (Figure 6l) does not affect the size of the eye field. However, in cul-4 loss-of-function background, misexpression of sgg (cul-4 $4^{\mathrm{J} 11-1-}$, ey>sgg) (Figures $6 \mathrm{j}$ and $\mathrm{k}$ ) or $d T C F^{D N}$ (cul-4 $4^{J 11-/-}$, ey $>d T C F^{D N}$ ), (Figures $6 m$ and $n$ ) resulted in a significant rescue of the cul-4 loss-of-function phenotype to a near wild-type eye. It suggests that cul-4 is involved in downregulation of $\mathrm{Wg}$ signaling in the eye. JNK is known to 
work in conjunction with $\mathrm{Wg}$ in multiple contexts including correction of morphogen gradient discontinuities; ${ }^{26}$ and differential levels of JNK signaling are associated with cell survival. $^{26,28}$

cul-4 prevents JNK-mediated cell death in the developing eye. We tested if JNK pathway is associated with the cul-4 loss-of-function phenotypes (Figure 7). We tested JNK levels in cul-4 loss-of-function background using puc (puc-lacZ) the downstream target, which serves as the functional readout for JNK pathway activation. ${ }^{30}$ In wild-type eye disc, puc is expressed in differentiated photoreceptor neurons of eye disc (Figure 7a). In cul-4 loss-of-function background, ectopic induction of puc was seen in the eye as well antenna disc (Figures $7 \mathrm{~b}$ and $\mathrm{b}^{\prime}$ ), suggesting that JNK signaling is activated in cul-4 mutant cells. To confirm, we checked levels of $p$-JNK, a reporter for activated JNK signaling, in western blots and found significant upregulation of $\mathrm{p}$-JNK levels in cul4 mutants compared with wild-type eye disc (Figure 7c). Blocking JNK signaling in the developing eye by misexpression of puc (ey>puc, Figure 7d) or bsk dominant negative $\left(b s k^{D N}\right)\left(e y>b s k^{D N} \text {, Figure } 7 g\right)^{25}$ did not affect the eye size. However, in cul-4 loss-of-function background misexpression of puc (cul-4 ${ }^{J J 11-/-}$, ey> puc, Figures 7e and e') or bsk $k^{D N}$ $\left(c^{\prime}{ }^{J J 11-/-}\right.$, ey $>b s k^{D N}$, Figures $7 \mathrm{~h}$ and $\left.\mathrm{h}^{\prime}\right)$, resulted in a significant rescue of cul-4 loss-of-function phenotype of reduced eye (Figure 2). Conversely, in cul-4 loss-of-function background activation of the JNK signaling pathway by misexpression of activated Jun (jun $\left.{ }^{\text {aspv7 }}\right)$ ( $\mathrm{cul}-4^{J J 11-/-}$, ey> jun ${ }^{a s p v 7}$ ) in the eye disc, strongly enhanced the reduced eye- to a 'no-eye' phenotype (Figures 7k and k'). Misexpression of $j u n^{a s p v 7}\left(e y>j u n^{a s p v 7}\right)$ alone in the eye results in a highly reduced eye field (Figure $7 \mathrm{j}$ ). It suggests that loss of cul-4 leads to activation of JNK signaling in the eye.

To confirm that activation of $\mathrm{Wg} / \mathrm{JNK}$ signaling pathway are both associated with the induction of cell death observed in cul-4 mutant cells, we monitored cell death using TUNEL assay when Wg (Figure 8) and JNK (Figure 9) levels are modulated in the wild-type, and in cul-4 mutant eye discs. We found that cell death is reduced when $\mathrm{Wg}$ or JNK signaling is downregulated in cul-4 mutant background. However, cell death is elevated when $\mathrm{Wg} / \mathrm{JNK}$ signaling is activated. Thus, cul-4 may be involved in limiting JNK as well as Wg activation in the developing eye disc, and thereby promote cell survival during development.

\section{Discussion}

Cul-4, an E3 ligase, is involved in regulation of chromatin function through heterochromatin gene silencing, maintenance of genomic integrity by promoting the ubiquitylation
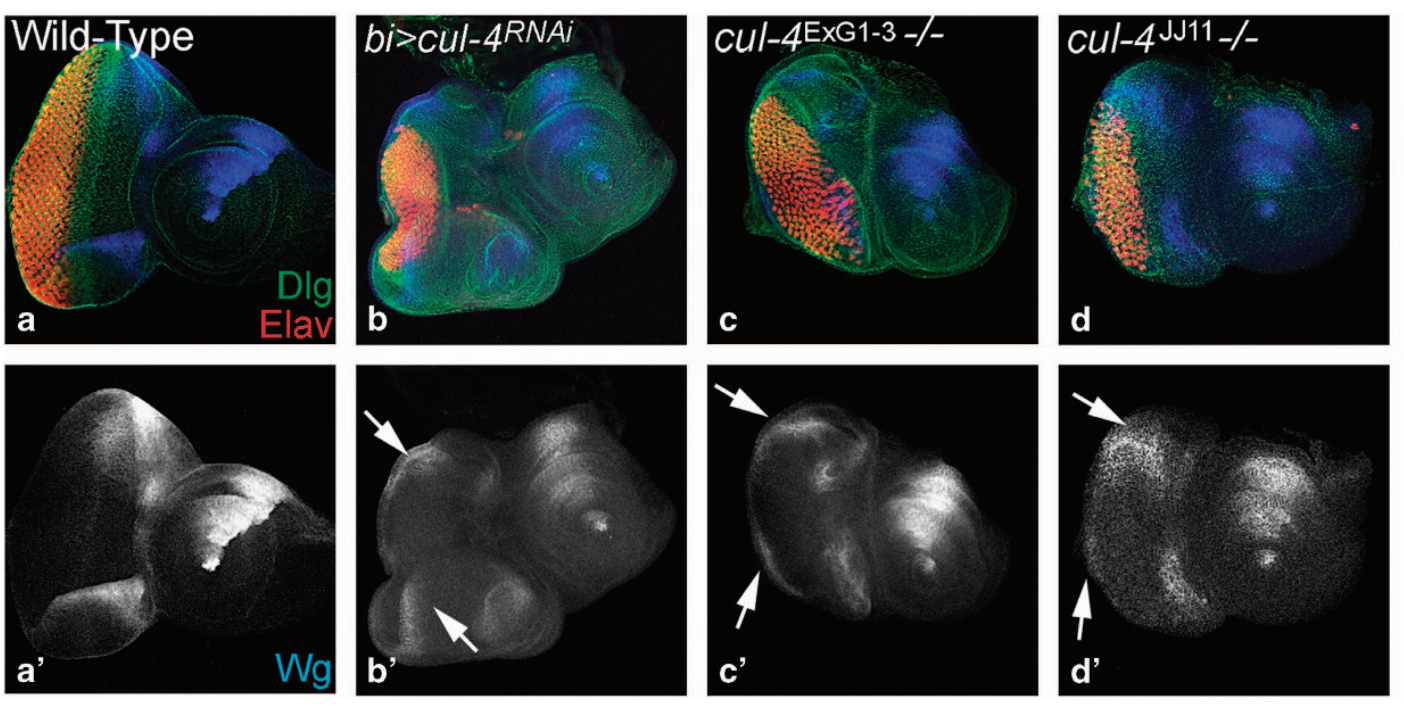

Figure 5 Wg is ectopically induced in cul-4 mutant background. Expression of Wg (blue) in (a, a') Wild-type, (b and b') bi $>$ cul4 ${ }^{\text {RNAi }}$, (cul--4 ${ }^{\mathrm{RNAi}}$ is misexpressed on DV margin using bi-Gal4), (c and $\left.\mathbf{c}^{\prime}\right)$ cul-4 $4^{E \times G 1}-3$ and (d and d') cul-4Jj11 loss-of-function clones. Note robust ectopic Wg (blue) expression on (b') DV margin (marked by white arrows) along with suppression of eye fate. (c and $\mathbf{d}$ ) The reduced eye phenotype of cul-4 loss-of-function clones generated by cell-lethal approach is accompanied by ectopic upregulation of $\mathrm{Wg}$ (blue, marked by white arrow). (a'-d') Shown is the split channel of Wg expression. (e) In western blot analysis, the Wg protein levels are more than twofolds in eye discs with cul-4 loss-of-function clones as compared with wild-type eye disc. Wg band staining intensity calculated by Image-J

Figure 6 Activation of Wg pathway results in the cul-4 mutant's reduced eye phenotype. (a) Cartoon showing Wg signaling pathway. (b) In the western blot performed by using protein extracts prepared from the wild-type and cul-4 mutant eye imaginal discs, the Armadillo (Arm) (a downstream cytoplasmic target of Wg signaling), protein levels are enhanced (twofold) in cul-4 loss-of-function background as compared with the wild-type (WT) control. Activation of Wg signaling by misexpression of (d and e) wg (cul-4 ${ }^{-1-}$;

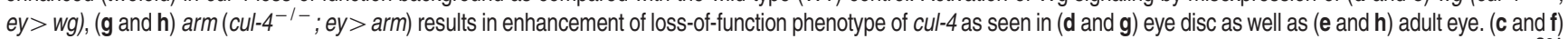
Misexpression of (c) $w g(e y>w g)$ and (f) arm (ey $>$ arm) results in small eye. Blocking Wg signaling by misexpression of negative regulators/ antagonists like (j and $\mathbf{k}) s g g^{59 \mathrm{~A}}$ $\left(\right.$ cul-4 $\left.{ }^{-1-} ; e y>s g g^{S 9 A}\right)$ and $(\mathbf{m}$ and $\mathbf{n}) d T C F^{D N}\left(\right.$ cul-4$\left.^{-1-} ; e y>d T C F^{D M}\right)$ suppresses the reduced eye phenotype of cul-4 loss-of-function to near normal as seen in (j and $\left.\mathbf{m}\right)$ eye disc and ( $\mathbf{k}$ and $\mathbf{n}$ ) adult eye. Misexpression of (i) $s g g\left(e y>s g g^{S 9 A}\right)$ and (I) $d T C F^{D N}\left(e y>d T C F^{D N}\right.$ ) results in normal eye sizes 

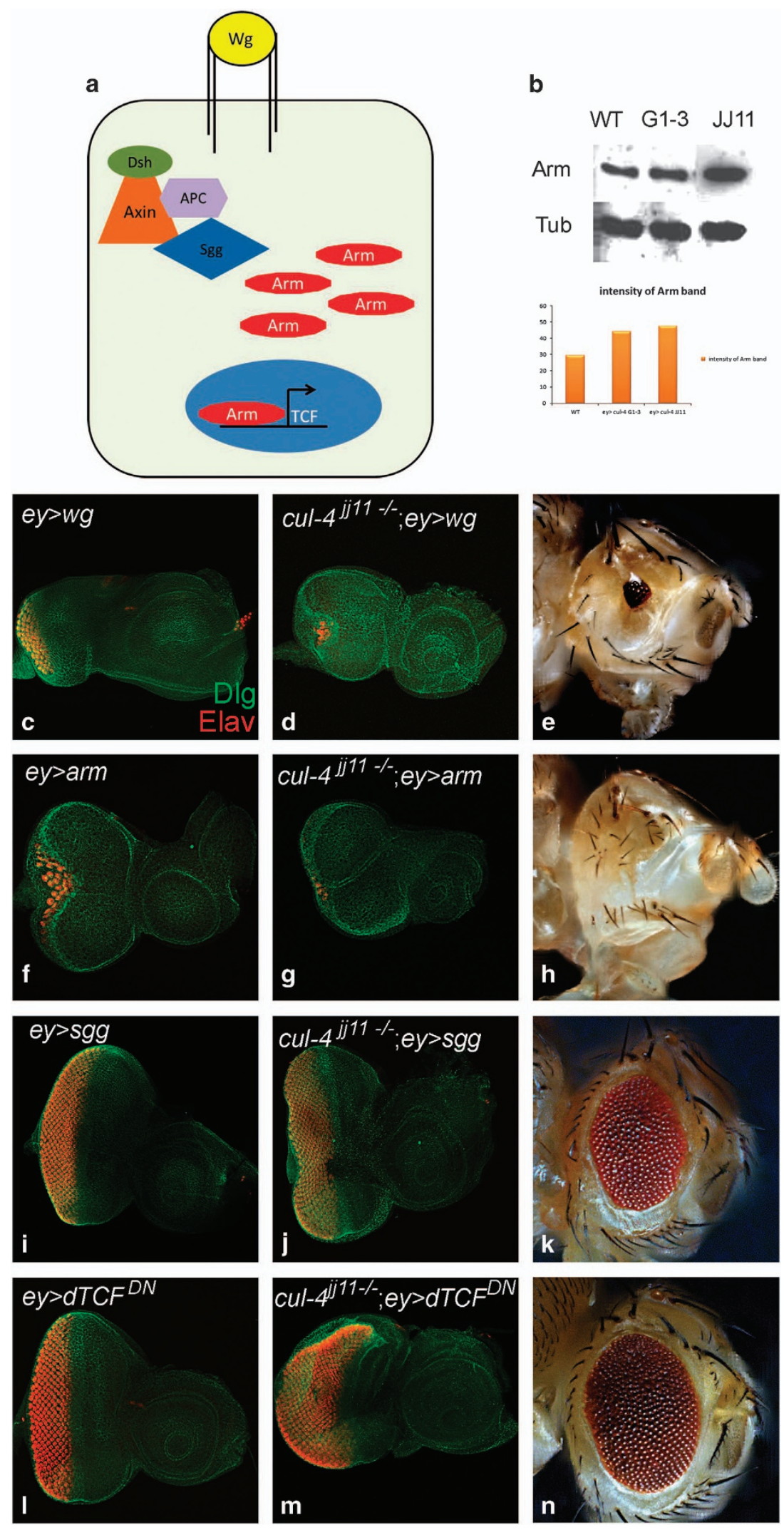

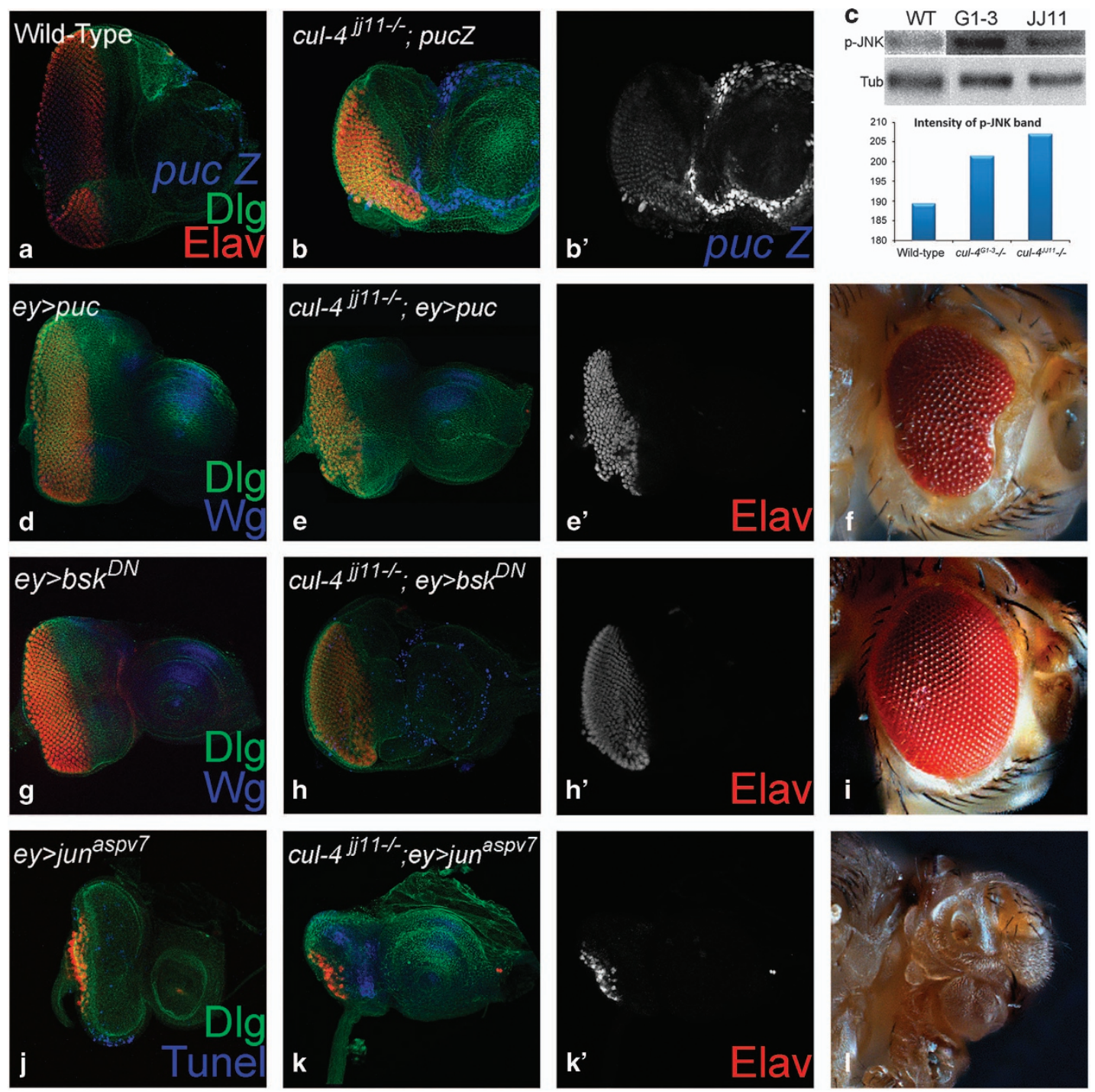

Figure 7 Aberrant JNK signaling in cul-4 loss-of-function background triggers cell death. (a) A functional readout of JNK signaling pathway, puc-lacZ (blue) is expressed in differentiated photoreceptor neurons (marked by Elav, red) in the wild-type eye discs. ${ }^{60}$ ( $\mathbf{b}$ and $\mathbf{b}$ ) Loss-of-function of cul-4 causes ectopic induction of puc-lacZ reporter in the eye imaginal disc. (c) Activation of JNK signaling was detected by analyzing phospho-Jun (p-JNK) levels in western blots. Twofold increase in the levels of JNK signaling pathway was

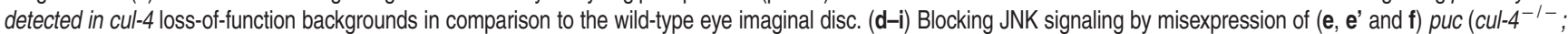

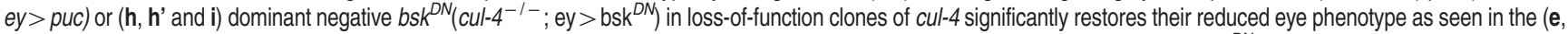
$\mathbf{e}^{\prime}, \mathbf{h}$ and $\mathbf{h}^{\prime}$ ) eye imaginal disc and the ( $\mathbf{f}$ and $\left.\mathbf{i}\right)$ adult flies. Misexpression of (d) puc (ey> puc) or (g) bsk dominant negative (ey>bsk ${ }^{D M}$ ) does not affect the eye size. (j-I) Misexpression of activated form of (j) jun (ey $>$ jun ${ }^{a s p v 7}$ ) in the developing eye results in reduced eye size, whereas (k, $\mathbf{k}^{\prime}$ and $\left.\mathbf{I}\right)$ misexpression of activated jun (cul-4 ${ }^{-1-}$; ey $>$ jun ${ }^{\text {aspvT }}$ ) results in further enhancement of cul-4 loss-of-function phenotype of reduced eye

and degradation of key cell cycle regulators. ${ }^{46-49} \mathrm{~A}$ number of ligases work in concert with the signaling pathways (Notch $(\mathrm{N})$, Hedgehog (Hh), Wg and so on) for regulating gene expression. For example, Slimb, is involved in regulating $\mathrm{Wg}$ and $\mathrm{Hh}$ signaling during eye development, ${ }^{50}$ Neuralized $(\mathrm{Neu})^{51}$ and Mind Bomb (Mib), are E3 ligases that are components of $\mathrm{N}$ signaling pathway; and are required for Drosophila eye development. ${ }^{52}$ Recently other functions for E3 ligases are being recognized. For example, DIAP1 regulates Dronc/Hid caspases, ${ }^{20,53}$ and is transcriptionally regulated by yorkie ( $\mathrm{yki}$ ) for survival function. ${ }^{54}$ DIAP-1 in turn, is regulated by Cul-3 in the developing eye to regulate apoptosis. ${ }^{71}$ Our studies provide evidences for a new function for cul-4 in cell survival during eye development.

Homozygous larvae of some cul-4 alleles are larval lethal that can survive until early third instar and produce smaller imaginal discs than wild-type discs at comparable developmental age. ${ }^{40}$ These phenotypes were attributed to problems with cell division. Our twin spot analysis revealed an interesting result that $\mathrm{cul}-4$ mutant tissues in the developing eye imaginal disc failed to survive (Figure 2), and are eliminated by activation of caspases (Figure 3). Generating cul-4 mutant clones by using multiple approaches (for example, eyeless and heat-shock flippase) validated that 

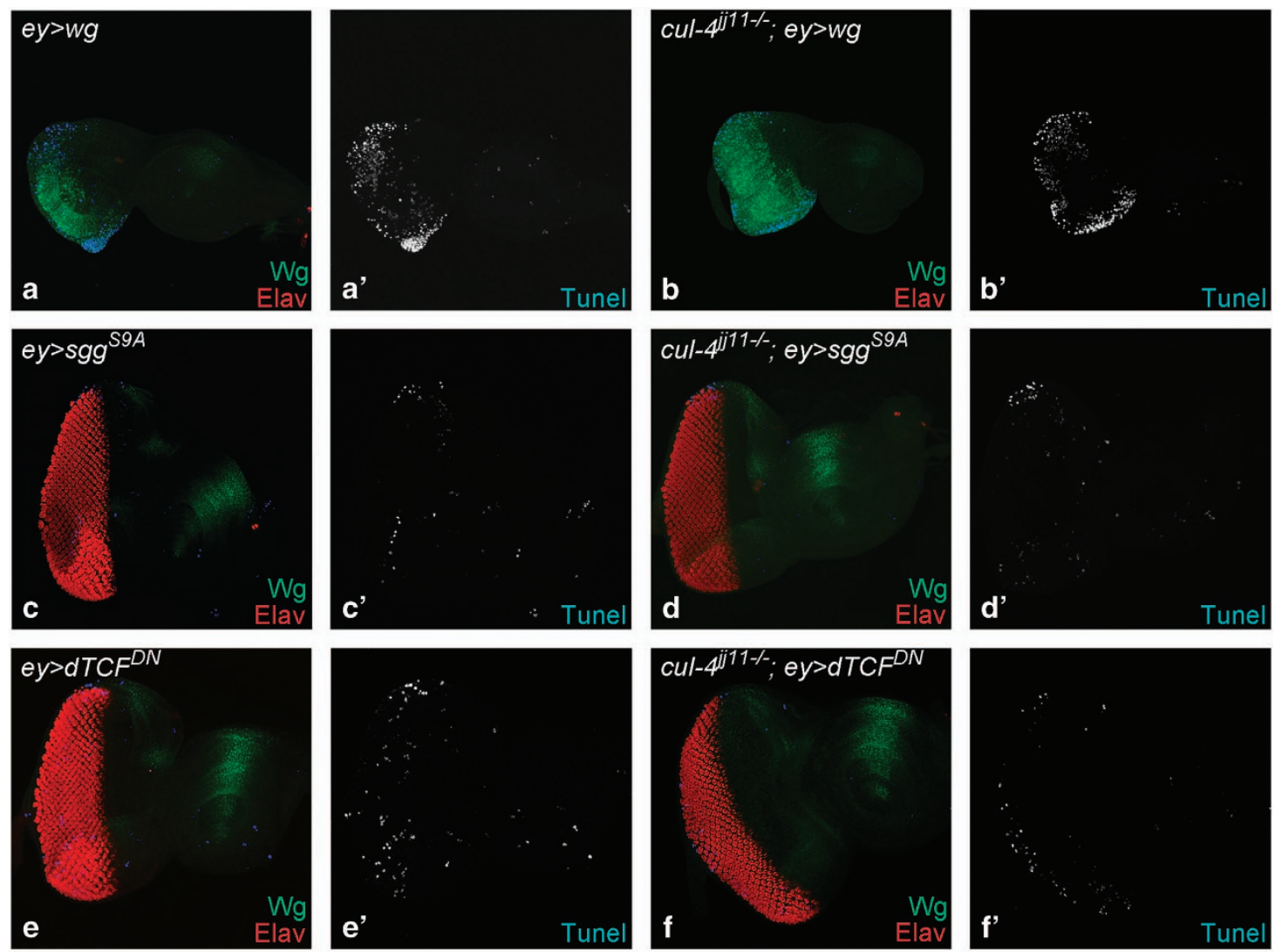

$\mathbf{g}_{300}$

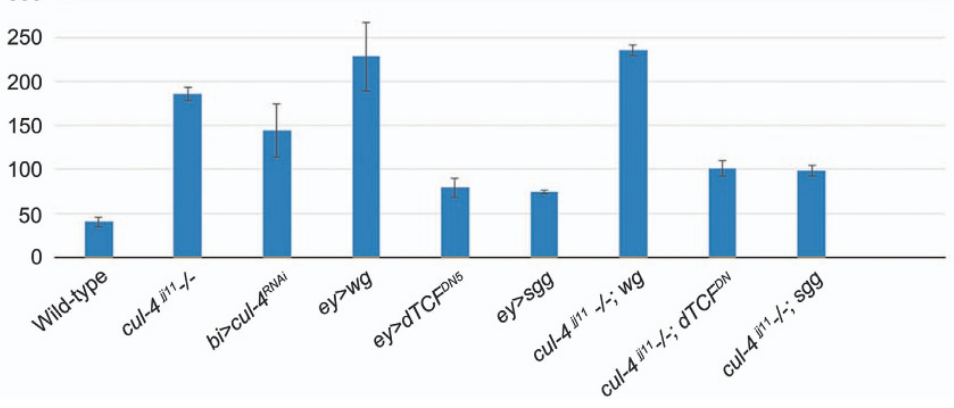

Figure 8 Aberrant Wg signaling triggers cell death in cul-4 loss-of-function background. Eye imaginal discs showing TUNEL (blue) labeling in (a and a') ey $>$ wg, (b and b')

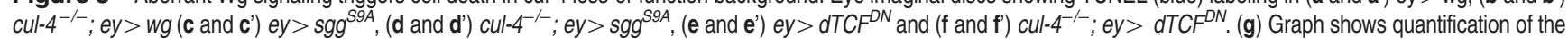
number of dying cells in the wild-type, cul-4 loss-of-function and genotypes shown in (a-f). Note that in cul-4 loss-of-function background cell death is enhanced when Wg is activated. Conversely, cell death is suppressed to near wild-type when Wg signaling is blocked in cul-4 loss-of-function background

cul-4 mutant cells failed to survive when generated in early embryonic or larval stages. Blocking caspase-mediated cell death led to significant rescue of reduced eye phenotypes of cul-4 loss-of-function (Figures $4 \mathrm{c}$ and d), supporting a role for cul-4 in cell survival.

We tested several cell signaling pathways in cul-4 loss-offunction background and found aberrant activation of $\mathrm{Wg}$ and JNK signaling (Figure 10). Wg is required for patterning, growth regulation and cell survival in multiple tissues including the eye discs. Ectopic induction of $\mathrm{Wg}$ induces cell death. $9,10,11,55$ We found that cells lacking cul-4 function also undergo cell death and they express high levels of Wg. Arm, the nuclear effector of the Wg signaling pathway, is a target of E3 ubiquitin ligase-mediated degradation. ${ }^{56}$ Loss-of-function phenotype of $c u l-4$ mutants could be modified by modulating the levels of canonical Wg signaling (Figures 6 and 7). Our data suggests that cul-4 may downregulate Wg signaling in the eye to promote cell survival in the eye disc. Since the cul-4 mutant phenotype was not completely rescued by blocking $\mathrm{Wg}$ signaling, we also tested the JNK signaling in the cul-4 mutant clones. The possibility of indirect consequences responsible for the mutant phenotype can be refuted because these phenotypes can be rescued by blocking $\mathrm{Wg}$ as well as JNKmediated cell death. We found that $\mathrm{Wg}$ levels were affected when JNK signaling was modulated in cul-4 mutant background (Figure 10a-c). However, the converse did not show effect on phospho-JNK levels (Figure 10d-f). Our studies generate insights into genetic mechanisms that regulate cell 

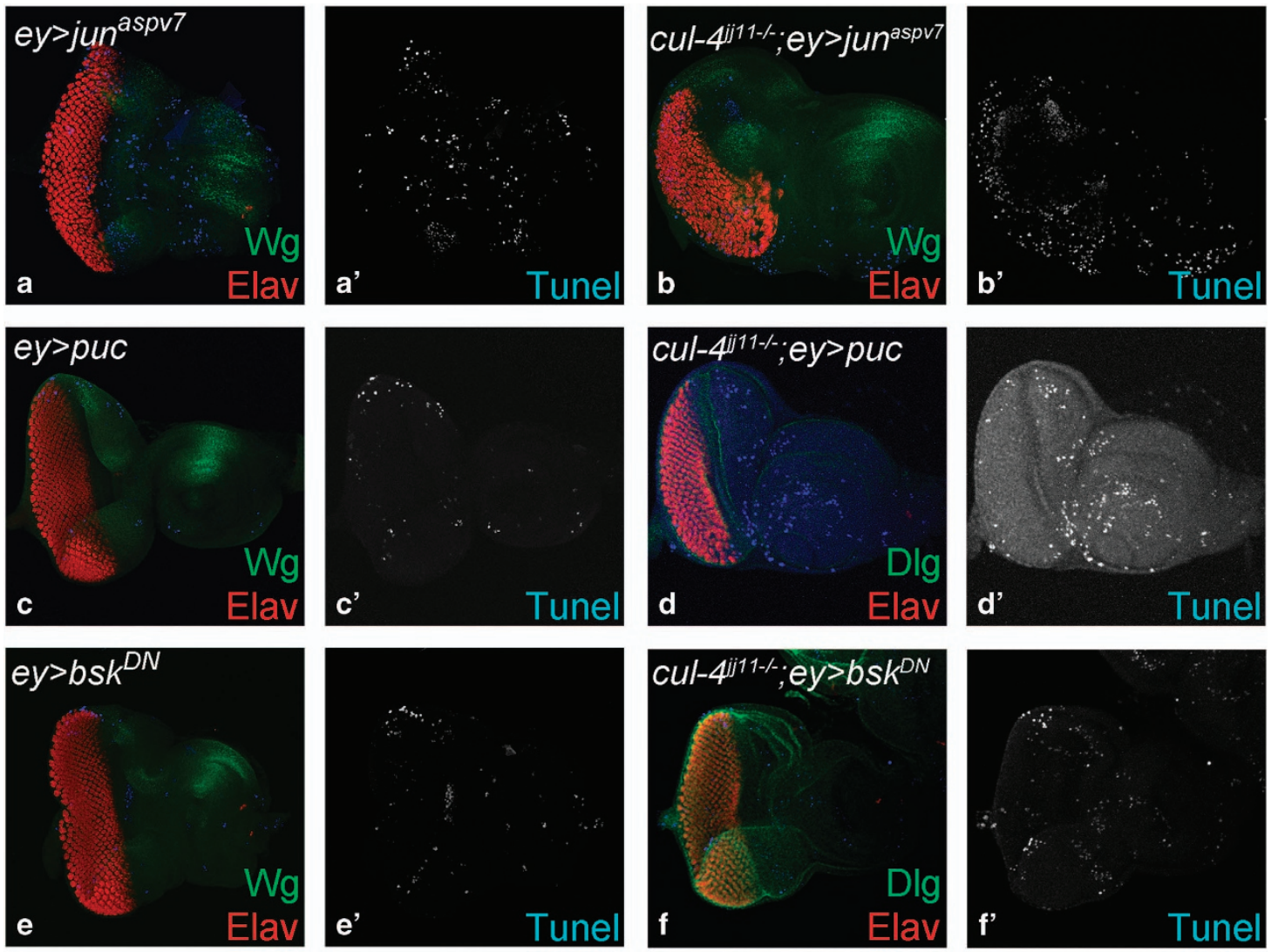

g

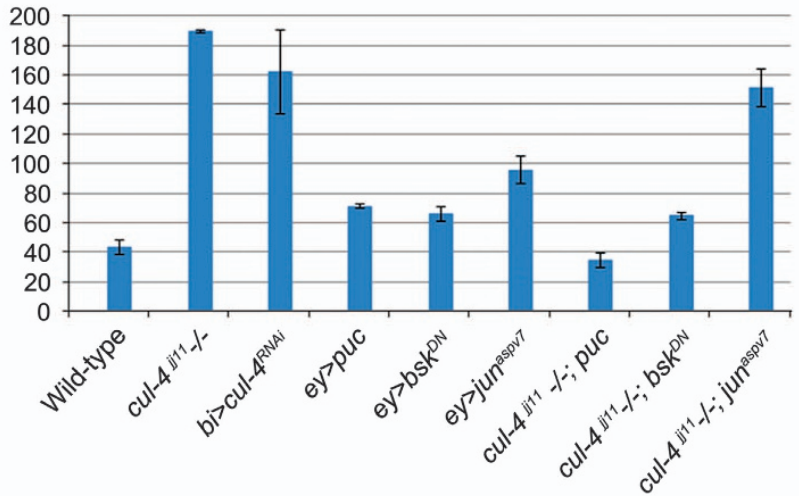

Figure 9 Aberrant JNK signaling triggers cell death in cul-4 loss-of-function background. Panels show TUNEL (blue) staining marking the dying cells nuclei in eye discs from

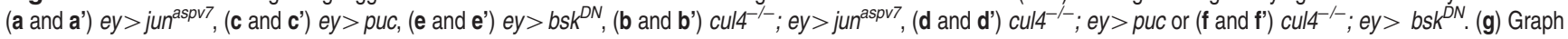
shows a comparison of the number of dying cells in wild-type, cul-4 loss-of-function and the genotypes shown in a-f. Note that rate of cell death is enhanced when JNK signaling is activated whereas the rate of cell death is suppressed when JNK signaling is blocked in cul-4 loss-of-function background

survival during normal development by demonstrating the role of cul-4 in preventing inappropriate upregulation of $\mathrm{Wg}$ and JNK signaling in the developing Drosophila eye during early stages (Figure 10). A recent study showed that loss of Godzilla, a member of the RNF family of membrane-anchored E3 ubiquitin ligases regulates $\mathrm{Wg}$ levels on the basolateral surface of the tissues through dynamin-dependent endocytosis from the apical surface and subsequent trafficking from early apical endosomes to the basolateral surface. ${ }^{57}$ Our studies also generate mechanistic insights into genetic mechanisms that regulate cell survival during normal development.

Numerous studies have shown the role of ubiquitinmediated proteolysis in a broad array of cellular processes like defects in organogenesis, growth, differentiation, metabolism and aging in all organisms. ${ }^{58}$ Abnormal protein homeostasis underlies various disorders ranging from growth defects to neurodegenerative disorders. ${ }^{59}$ Our studies introduced new role of cul-4 in cell survival in the developing Drosophila eye. Since Drosophila serves as an excellent model to study 

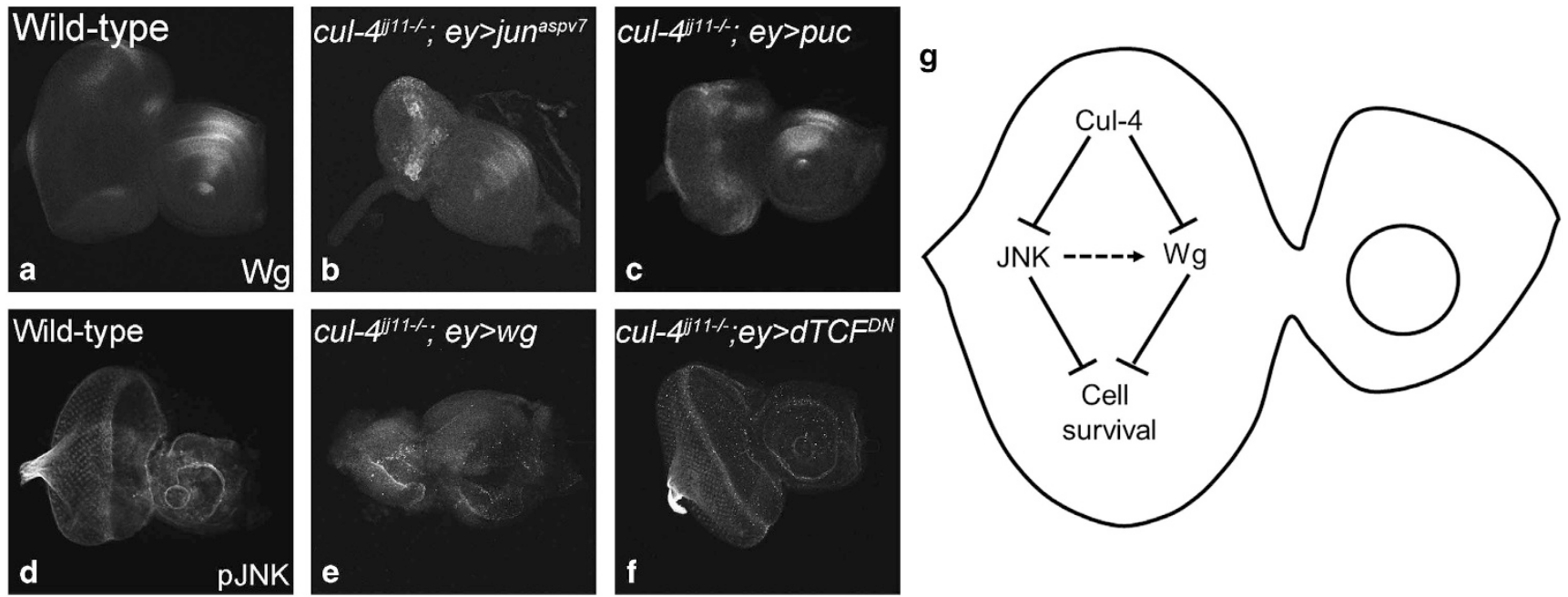

Figure 10 cul-4 promotes cell survival by regulating wg and JNk signaling in the developing eye. (a-c) Wg expression in (a) wild-type, (b) cull-4 $^{-/-}$; ey> jun ${ }^{\text {aspv7 }}$; and (c) cul$4^{-\gamma}$; ey> puc eye imaginal disc. Note that Wg levels are upregulated when JNK signaling is activated, whereas Wg levels are not much affected when JNK signaling is

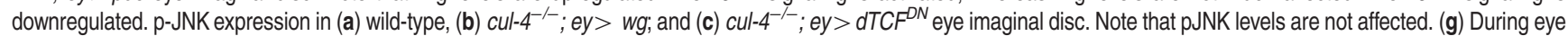
development cul-4 is involved in (i) downregulating Wg signaling and (ii) inhibiting JNK signaling to promote cell survival. Activated JNK signaling can trigger Wg induction

development and human disease, ${ }^{60}$ these studies may shed light on understanding genetic basis of neurodegenerative orders in future.

\section{Materials and Methods}

Fly stocks. The fly stocks used are described on Flybase (http://flybase.bio. indiana.edu). Cul-4 stocks used are EP 2518 (UAS-cul-4); cul-4 RNAi lines 8711 and $8711-\mathrm{R} 1$ (from NIG). ${ }^{61}$ The $\mathrm{N}$-terminal deletion mutants used were cul-4 ExG1-3/CyO, which lack 340 amino acids from amino terminal. cul-4 ${ }^{J 11} /$ twi $>$ GFP, CyO carries a nonsense mutation at Trp199 position. ${ }^{40}$

Other stocks include Canton-S, y w eyFLP, ${ }^{39} L^{2} / C y 0,{ }^{37,62}$ wg-lacZ/CyO ${ }^{63}$ UAS-wg, ${ }^{64}$

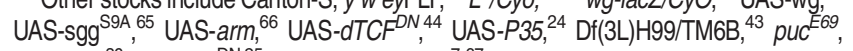
UAS-puc, ${ }^{30}$ 'UAS-bsk ${ }^{\mathrm{NN}, 25}$ and UAS-DJun ${ }^{\text {aspvi } 67}{ }^{67}$ The Gal4/UAS system was used for targeted misexpression studies ${ }^{38}$ using ey-Gal4, ${ }^{65}$ and bi-Gal4 (refs 41,42 ) lines.

Mosaic analysis. To generate loss-of-function clones $^{68}$ of cul-4 in the eye, virgins of eyFlp; FRT42D, cl-w $/$ CyO-GFP were crossed to (i) FRT 42D, cul-4 ExG1-3/ CyO, (ii) FRT 42D, cul-4 ExG3-5, (iii) FRT 42D, cul-4 ExL2-1/CyO and (iv) FRT 42D, cul-4 ${ }^{\mathrm{J} 11} /$ twi $>$ GFP, CyO.

Twin spot analysis. We used hsFlp; FRT42D ubi-GFP to generate loss-offunction clones of cul-4 ${ }^{\text {ExG1-3 }}$ and $\mathrm{Cul}^{-4}{ }^{\mathrm{J} 11}$ in the eye imaginal disc at different larval development stages. Egg laying were collected from synchronous cultures maintained at $25^{\circ} \mathrm{C}$. The cultures were heat shocked at 24 and $48 \mathrm{~h}$ after egg laying (AEL) at $37^{\circ} \mathrm{C}$ for $50 \mathrm{~min}$ in order to induce loss-of-function clones. Eye discs were dissected in second and third-instar stages to analyze/identify cul-4 loss-offunction clones marked by the absence of GFP expression.

Immunohistochemistry. Eye-antennal imaginal discs were dissected from wandering third-instar larvae and stained following the standard protocol. ${ }^{62}$ Antibodies used were rat anti-Elav (1:100), mouse anti-Wg (1:50), mouse anti- $\beta$ galactosidase (1:200) (Developmental Studies Hybridoma Bank, DSHB, lowa City, IA, USA), rabbit anti-Dlg (1:250) (gift from Kyung- Ok Cho), rat anti-Mirror (1:200) (gift from Kwang Wook Choi), rabbit anti-caspase- $3^{*}$ (1:200) and rabbit PhosphoSAPK/JNK (Cell Signaling Thr183/Tyr185) (81E11) (Cell Signaling Technology, Danvers, MA, USA). Secondary antibodies (Jackson Immuno Research Laboratories Inc., West Grove, PA, USA) were goat anti-rat IgG conjugated with Cy5 (1:200), donkey anti-rabbit IgG conjugated to Cy3 (1:250), donkey anti-rabbit IgG conjugated to FITC and donkey anti-mouse IgG conjugated to Cy3 (1:200). The discs were mounted in Vectashield (Vector Laboratories Inc., Burlingame, CA, USA) and imaged using Olympus Fluoview 1000 microscope (Olympus America, Scientific Solutions Group, Center Valley, PA, USA). Images were analyzed using the Adobe Photoshop CS4 (Adobe Systems, San Jose, CA, USA) and image intensity was calculated using the Image $\mathrm{J}$ software.

TUNEL assays. Apoptotic cell death was assayed using TUNEL assays in the mutant clones generated via twin spot analysis and cell lethal approach. Eye discs, after secondary antibody staining, ${ }^{62}$ were blocked in $10 \%$ Normal Goat Serum in Phosphate Buffered Saline with 0.2\% Triton X-100.TUNEL assays were done using the Cell-death Detection Kit from Roche Diagnostics following the standardized protocol. ${ }^{11,17}$ The TUNEL-positive nuclei were counted from five eye imaginal discs for each genotype using Image-J and statistical analysis was performed using Microsoft Excel 2013. The P-values were calculated and the error bars represent Standard Deviation.

Adult eye imaging. Adult Drosophila eye images were taken ${ }^{70}$ using a Zeiss Apotome Imager.Z1 microscope (Carl Zeiss Microscopy GmbH, Jena, Germany). The flies were prepared by freezing them at $-20^{\circ} \mathrm{C}$ for $\sim 2 \mathrm{~h}$. The legs and wings of the flies were removed and flies were mounted on a dissection needle, and the fly was positioned on a glass slide using mounting putty. Images were captured by using extended depth of focus function of the Axiovision software version 4.6.3 (Carl Zeiss Microscopy GmbH, Jena, Germany) by compiling the individual stacks from the Z-sectioning approach. The final images and figures were prepared using Adobe Photoshop CS4 software.

Western blot analysis. Protein samples were prepared from third-instar eyeantennal imaginal discs of different cul-4 mutants dissected in ice-cold PBS. Samples were transferred to sample buffer containing SDS- $\beta$-mercaptoethanol, boiled for $10 \mathrm{~min}$, stored in $-80^{\circ} \mathrm{C}$. Protein samples were separated on $10 \%$ SDSPAGE and transferred to nitrocellulose membrane. The membrane was blocked in blocking solution (AMRESCO LLC, Solon, OH, USA) and incubated with primary antibody. The antibodies used were anti- mouse Wg (1:100) (DSHB); anti-mouse arm (1:2000) (DSHB), anti-rabbit p-JNK (1:2000) (Cell signaling Technologies), antirabbit Caspase-9 (1:1000) (Cell signaling Technologies) or anti- mouse tubulin (1:5000) (Sigma-Aldrich Corp., St. Louis, MO, USA). Secondary antibodies were horseradish peroxidaseconjugated goat anti-rabbit IgG, and the signal was detected using super-signal chemiluminiscence substrate (Pierce Biotechnology, Thermofisher Scientific, Rockford, IL USA).

\section{Conflict of Interest}

The authors declare no conflict of interest.

Acknowledgements. We thank, Chen Ting-Chen, Robert J Duronio, Tin Tin $\mathrm{Su}$, the Bloomington Stock Center for the Drosophila strains, K Cho and the 
Developmental Studies Hybridoma Bank (DSHB) for the antibodies. We thank members of the Singh laboratory for critical comments on the manuscript. Confocal microscopy was supported by Biology Department central core facility. MK-S is supported by Knight's Templar Ophthalmology Research Foundation and startup support from UD. This work is supported by start-up support from UD, and Ohio Cancer Research Associates to AS.

\section{Author contributions}

MT performed majority of the experiments and the data analysis. AS performed experiments. SB performed experiments. MK-S did the data analysis and the manuscript writing. AS developed the concept and did the data analysis and manuscript writing.

1. Ready DF, Hanson TE, Benzer S. Development of the Drosophila retina, a neurocrystalline lattice. Dev Biol 1976; 53: 217-240.

2. Ma C, Moses K. Wingless and patched are negative regulators of the morphogenetic furrow and can affect tissue polarity in the developing Drosophila compound eye. Development 1995; 121: 2279-2289.

3. Tare M, Puli OR, and, Singh A. Molecular genetic mechanisms of axial patterning: mechanistic insights into generation of axes in the developing eye. In: Singh A, and KangoSingh M (eds). Molecular Genetics of Axial Patterning, Growth and Disease in the Drosophila Eye. Springer: NewYork, 2013, pp 37-75.

4. Treisman JE, Rubin GM. wingless inhibits morphogenetic furrow movement in the Drosophila eye disc. Development 1995; 121: 3519-3527.

5. Aberle H, Bauer A, Stappert J, Kispert A, Kemler R. Beta-catenin is a target for the ubiquitinproteasome pathway. EMBO J 1997; 16: 3797-3804.

6. Archbold HC, Yang YX, Chen L, Cadigan KM. How do they do Wnt they do?: regulation of transcription by the Wnt/beta-catenin pathway. Acta Physiol (Oxf) 2011; 204: 74-109.

7. Swarup S, Verheyen EM. Drosophila homeodomain-interacting protein kinase inhibits the Skp1-Cul1-F-box E3 ligase complex to dually promote Wingless and Hedgehog signaling. Proc Natl Acad Sci USA 2011; 108: 9887-9892.

8. Cordero J, Jassim O, Bao S, Cagan R. A role for wingless in an early pupal cell death event that contributes to patterning the Drosophila eye. Mech Dev 2004; 121: 1523-1530.

9. Lin HV, Rogulja A, Cadigan KM. Wingless eliminates ommatidia from the edge of the developing eye through activation of apoptosis. Development 2004; 131: 2409-2418.

10. Ryoo HD, Gorenc T, Steller H. Apoptotic cells can induce compensatory cell proliferation through the JNK and the Wingless signaling pathways. Dev Cell 2004; 7: 491-501.

11. Singh A, Shi X, Choi KW. Lobe and Serrate are required for cell survival during early eye development in Drosophila. Development 2006; 133: 4771-4781.

12. Singh A, Lim J, Choi K-W. Dorso-ventral boundary is required for organizing growth and planar polarity in the Drosophila eye. In: Mlodzik M (ed). Planar Cell Polarization during Development: Advances in Developmental Biology and Biochemistry. Elsevier Science \& Technology Books: New York, 2005, pp 59-91.

13. Singh A, Tare M, Puli OR, Kango-Singh M. A glimpse into dorso-ventral patterning of the Drosophila eye. Dev Dyn 2012; 241: 69-84.

14. Arya R, White K. Cell death in development: signaling pathways and core mechanisms. Semin Cell Dev Biol 2015; 39: 12-19.

15. Chen P, Nordstrom W, Gish B, Abrams JM. Grim, a novel cell death gene in Drosophila. Genes Dev 1996; 10: 1773-1782.

16. Grether ME, Abrams JM, Agapite J, White K, Steller H. The head involution defective gene of Drosophila melanogaster functions in programmed cell death. Genes Dev 1995; 9 : 1694-1708.

17. White K, Grether ME, Abrams JM, Young L, Farrell K, Steller H. Genetic control of programmed cell death in Drosophila. Science 1994; 264: 677-683.

18. Holley CL, Olson MR, Colon-Ramos DA, Kornbluth S. Reaper eliminates IAP proteins through stimulated IAP degradation and generalized translational inhibition. Nat Cell Biol 2002; 4: 439-444.

19. Yoo SJ, Huh JR, Muro I, Yu H, Wang L, Wang SL et al. Hid, Rpr and Grim negatively regulate DIAP1 levels through distinct mechanisms. Nat Cell Biol 2002; 4: 416-424.

20. Goyal L, McCall K, Agapite J, Hartwieg E, Steller H. Induction of apoptosis by Drosophila reaper, hid and grim through inhibition of IAP function. EMBO J 2000; 19: 589-597.

21. Chew SK, Akdemir F, Chen P, Lu WJ, Mills K, Daish T et al. The apical caspase dronc governs programmed and unprogrammed cell death in Drosophila. Dev Cell 2004; 7: 897-907.

22. Daish TJ, Mills K, Kumar S. Drosophila caspase DRONC is required for specific developmental cell death pathways and stress-induced apoptosis. Dev Cell 2004; 7: 909-915.

23. Xu D, Li Y, Arcaro M, Lackey M, Bergmann A. The CARD-carrying caspase Dronc is essential for most, but not all, developmental cell death in Drosophila. Development 2005; 132: 2125-2134.

24. Hay BA, Wolff T, Rubin GM. Expression of baculovirus P35 prevents cell death in Drosophila. Development 1994; 120: 2121-2129.

25. Adachi-Yamada T, Fujimura-Kamada K, Nishida Y, Matsumoto K. Distortion of proximodistal information causes JNK-dependent apoptosis in Drosophila wing. Nature 1999; 400: 166-169.
26. Adachi-Yamada T, O'Connor MB. Mechanisms for removal of developmentally abnormal cells: cell competition and morphogenetic apoptosis. J Biochem 2004; 136: 13-17.

27. Tare M, Modi RM, Nainaparampil JJ, Puli OR, Bedi S, Fernandez-Funez P et al. Activation of JNK signaling mediates amyloid-ss-dependent cell death. PloS One 2011; 6: e24361.

28. Igaki T. Correcting developmental errors by apoptosis: lessons from Drosophila JNK signaling. Apoptosis 2009; 14: 1021-1028.

29. Igaki T, Miura M. The Drosophila TNF ortholog Eiger: emerging physiological roles and evolution of the TNF system. Semin Immunol 2014; 26: 267-274.

30. Martin-Blanco E, Gampel A, Ring J, Virdee K, Kirov N, Tolkovsky AM et al. puckered encodes a phosphatase that mediates a feedback loop regulating JNK activity during dorsal closure in Drosophila. Genes Dev 1998; 12: 557-570.

31. Singh A, Chan J, Chern JJ, Choi KW. Genetic interaction of Lobe with its modifiers in dorsoventral patterning and growth of the Drosophila eye. Genetics 2005; 171: 169-183.

32. Jackson S, Xiong Y. Targeting protein ubiquitylation: DDB1 takes its RING off. Nat Cell Biol 2009; 11: 379-381.

33. Abbas T, Keaton M, Dutta A. Regulation of TGF-beta signaling, exit from the cell cycle, and cellular migration through cullin cross-regulation: SCF-FBXO11 turns off CRL4-Cdt2. Cell Cycle 2013; 12: 2175-2182.

34. Braun S, Garcia JF, Rowley M, Rougemaille M, Shankar S, Madhani HD. The Cul4-Ddb1 (Cdt)(2) ubiquitin ligase inhibits invasion of a boundary-associated antisilencing factor into heterochromatin. Cell 2011; 144: 41-54.

35. Swanson $\mathrm{Cl}$, Duronio RJ. Developmental regulation of replication-coupled protein destruction. Cell Cycle 2011; 10: 859-860.

36. Zielke N, Kim KJ, Tran V, Shibutani ST, Bravo MJ, Nagarajan S et al. Control of Drosophila endocycles by E2F and CRL4(CDT2). Nature 2011; 480: 123-127.

37. Singh A, Choi KW. Initial state of the Drosophila eye before dorsoventral specification is equivalent to ventral. Development 2003; 130: 6351-6360.

38. Brand $\mathrm{AH}$, Perrimon N. Targeted gene expression as a means of altering cell fates and generating dominant phenotypes. Development 1993; 118: 401-415.

39. Newsome TP, Asling B, Dickson BJ. Analysis of Drosophila photoreceptor axon guidance in eye-specific mosaics. Development 2000; 127: 851-860.

40. Lin HC, Wu JT, Tan BC, Chien CT. Cul4 and DDB1 regulate Orc2 localization, BrdU incorporation and Dup stability during gene amplification in Drosophila follicle cells. J Cell Sci 2009; 122: 2393-2401.

41. Lecuit T, Brook WJ, Ng M, Calleja M, Sun H, Cohen SM. Two distinct mechanisms for long-range patterning by Decapentaplegic in the Drosophila wing. Nature 1996; 381: 387-393.

42. Tare M, Puli OR, Moran MT, Kango-Singh M, Singh A. Domain specific genetic mosaic system in the Drosophila eye. Genesis 2013; 51: 68-74.

43. Abbott MK, Lengyel JA. Embryonic head involution and rotation of male terminalia require the Drosophila locus head involution defective. Genetics 1991; 129: 783-789.

44. van de Wetering M, Cavallo R, Dooijes D, van Beest M, van Es J, Loureiro J et al. Armadillo coactivates transcription driven by the product of the Drosophila segment polarity gene dTCF. Cell 1997; 88: 789-799.

45. Heslip TR, Theisen H, Walker H, Marsh JL. Shaggy and dishevelled exert opposite effects on Wingless and Decapentaplegic expression and on positional identity in imaginal discs. Development 1997; 124: 1069-1078.

46. Higa LA, Zhang H. Stealing the spotlight: CUL4-DDB1 ubiquitin ligase docks WD40-repeat proteins to destroy. Cell Div 2007; 2: 5 .

47. Hu J, Zacharek S, He YJ, Lee H, Shumway S, Duronio RJ et al. WD40 protein FBW5 promotes ubiquitination of tumor suppressor TSC2 by DDB1-CUL4-ROC1 ligase. Genes Dev 2008; 22: 866-871.

48. Kim J, Kipreos ET. Control of the Cdc6 replication licensing factor in metazoa: the role of nuclear export and the CUL4 ubiquitin ligase. Cell cycle 2008; 7: 146-150.

49. Shibutani ST, de la Cruz AF, Tran V, Turbyfill WJ 3rd, Reis T, Edgar BA et al. Intrinsic negative cell cycle regulation provided by PIP box- and Cul4Cdt2-mediated destruction of E2f1 during S phase. Dev Cell 2008; 15: 890-900.

50. Jiang J, Struhl G. Regulation of the Hedgehog and Wingless signalling pathways by the F-box/WD40-repeat protein Slimb. Nature 1998; 391: 493-496.

51. Cho B, Fischer JA. Ral GTPase promotes asymmetric Notch activation in the Drosophila eye in response to Frizzled/PCP signaling by repressing ligand-independent receptor activation. Development 2011; 138: 1349-1359.

52. Nagaraj R, Banerjee U. Combinatorial signaling in the specification of primary pigment cells in the Drosophila eye. Development 2007; 134: 825-831.

53. Wang SL, Hawkins CJ, Yoo SJ, Muller HA, Hay BA. The Drosophila caspase inhibitor DIAP1 is essential for cell survival and is negatively regulated by HID. Cell 1999; 98: 453-463.

54. Huang J, Wu S, Barrera J, Matthews K, Pan D. The Hippo signaling pathway coordinately regulates cell proliferation and apoptosis by inactivating Yorkie, the Drosophila Homolog of YAP. Cell 2005; 122: 421-434.

55. Mehlen $P$, Mille $F$, Thibert $C$. Morphogens and cell survival during development. J Neurobiol 2005; 64: 357-366.

56. Jumpertz S, Hennes T, Asare $Y$, Vervoorts J, Bernhagen J, Schutz AK. The beta-catenin E3 ubiquitin ligase SIAH-1 is regulated by CSN5/JAB1 in CRC cells. Cell Signal 2014; 26: 2051-2059.

57. Yamazaki Y, Palmer L, Alexandre C, Kakugawa S, Beckett K, Gaugue I et al. Godzilladependent transcytosis promotes Wingless signalling in Drosophila wing imaginal discs. Nat Cell Biol 2016; 18: 451-457. 
58. Varshavsky A. The ubiquitin system, an immense realm. Annu Rev Biochem 2012; 81: 167-176.

59. Dennissen FJ, Kholod N, van Leeuwen FW. The ubiquitin proteasome system in neurodegenerative diseases: culprit, accomplice or victim? Prog Neurobiol 2012; 96: 190-207.

60. Singh A, Irvine KD. Drosophila as a model for understanding development and disease. Dev Dyn 2012; 241: 1-2.

61. Zhang J, Liu M, Su Y, Du J, Zhu AJ. A targeted in vivo RNAi screen reveals deubiquitinases as new regulators of Notch signaling. G3 (Bethesda) 2012; 2: 1563-1575.

62. Singh A, Kango-Singh M, Sun YH. Eye suppression, a novel function of teashirt, requires Wingless signaling. Development 2002; 129: 4271-4280.

63. Kassis JA, Noll E, VanSickle EP, Odenwald WF, Perrimon N. Altering the insertional specificity of a Drosophila transposable element. Proc Natl Acad Sci USA 1992; 89: 1919-1923.

64. Azpiazu N, Morata G. Functional and regulatory interactions between Hox and extradenticle genes. Genes Dev 1998; 12: 261-273.

65. Hazelett DJ, Bourouis M, Walldorf U, Treisman JE. decapentaplegic and wingless are regulated by eyes absent and eyegone and interact to direct the pattern of retinal differentiation in the eye disc. Development 1998; 125: 3741-3751.

66. Zecca M, Basler K, Struhl G. Direct and long-range action of a wingless morphogen gradient. Cell 1996; 87: 833-844.

67. Treier M, Bohmann D, Mlodzik M. JUN cooperates with the ETS domain protein pointed to induce photoreceptor R7 fate in the Drosophila eye. Cell 1995; 83: 753-760.

68. Blair SS. Genetic mosaic techniques for studying Drosophila development. Development 2003; 130: 5065-5072.
69. Xu T, Rubin GM. Analysis of genetic mosaics in developing and adult Drosophila tissues. Development 1993; 117: 1223-1237.

70. Steffensmeier AM, Tare M, Puli OR, Modi R, Nainaparampil J, Kango-Singh M et al. Novel neuroprotective function of apical-basal polarity gene crumbs in amyloid beta 42 (abeta42) mediated neurodegeneration. PloS One 2013; 8: e78717.

71. Fan Y, Bergmann A. Multiple Mechanisms Modulate Distinct Cellular Susceptibilities toward Apoptosis in the Developing Drosophila Eye. Dev Cell 2014; 30: 48-60.

(1) Cell Death and Disease is an open-access journal published by Nature Publishing Group. This work is licensed under a Creative Commons Attribution 4.0 International License. The images or other third party material in this article are included in the article's Creative Commons license, unless indicated otherwise in the credit line; if the material is not included under the Creative Commons license, users will need to obtain permission from the license holder to reproduce the material. To view a copy of this license, visit http://creativecommons.org/licenses/by/4.0/

(C) The Author(s) 2016

Supplementary Information accompanies this paper on Cell Death and Disease website (http://www.nature.com/cddis) 